\title{
Museums BeTYDNiNG - DEN FRAKTALE UDFORDRING
}

\author{
Carsten Paludan-Müller
}

"Den moderne tids poeter var på jagt efter forandringens princip; i den epoke, som nu er $i$ sin begyndelse, søger vi digtere det uforanderlige princip, som er grundlaget for forandringerne.» (Octavio Paz 1993)

"Udviklingen vil bestandigt have tilfeldighedens karakter. Det er derfor fremskridtene $i$ kompleksitet er marginale fonomener, statistisk ubetydelige og $i$ den forstand "usandsynlige»; fejltagelserne er langt hyppigere end succeserne, fremskridtene vil altid vare usikre.» (Edgar Morin 1990)

"Historien gentager sig ikke mekanisk, men den producerer konstanter, for nu at bruge et affysikkens begreber: Konstanter i adfard, konstanter i risici, konstanter i attituder. At kende disse er et af de fä midler, ikke til at beherske tilfaldighedernes spil, men til at forberede sig på dem: Kriserne lader sig ikke forudse, men forstäelsen af de, der allerede har udspillet sig, udgør den bedst mulige forberedelse.» (Alain Minc 1993)

Tro på fremskridtet, tro på fremtiden, tillid til den moderne europæiske livsforms historiske overlegenhed. Det er kendemærkerne for rationalismens og industrialismens tidsalder. Det er den, som museerne er født af - som en af dens prominente manifestationer.

Industrialismens ungdom var $\mathrm{i}$ sagens natur præget af forandring og opbrud men en forandring, der kunne tydes aksialt som et retningsbestemt led $i$ en historisk evolutionær drift frem mod et stadigt højere civilisatorisk niveau. Museernes bi- drag til tidens selvforståelse var væsentligt: de gjorde forandringen retningsbestembar med deres udstillinger, der ordnede fænomenerne i forsimplende koordinatsystemer af tider og steder efter indbyrdes udmålte afstande. De leverede læsbar dokumentation for opfattelsen af samtidens europæiske kultur som historiens foreløbige kulminationspunkt i tid og rum. Deraf springer en væsentlig del af museernes betydning og anseelse $i$ forrige århundrede og gennem hovedparten af dette. 
HISTORIENS DØD, ELLER DEN TABTE TID

I dag er vi så på vej ind i en ny tidsalder med disse museer som er børn af et tidligere opbrud. Denne gang synes opbruddet blot ikke klart og entydigt retningsbestemt mod fremskridtet. Opbruddet er ikke aksialt - snarere fraktalt, det vil sige flertydigt. Alain Minc (forfatter til Le Nouveau Moyen Age, 1993) fremhævede i et nyligt interview et nyt frenomen: Nutidens forældre tror ikke, at deres børn vil få et bedre voksenliv end de selv - de vil ikke erfare fremskridtet. Vi oplever en stadigt accelererende strøm af teknologiske gennembrud, men oplever også tvivl og rådvildhed om disse gennembruds evne til at forebygge eller afhjælpe sammenbruddene - de økologiske, økonomiske og sociale, der truer millioner af mennesker kloden over - også i den rige verdens byer.

Netop det teknologiske fremskridt - for eksempel i form af satellittransmitterede billeder fra Rwanda eller Bosnien - har konfronteret os med afmagten. Paul Virillo (1993) beskriver det som en sammenstyrtning (implosion) af tid og rum men det rum, medierne lader os færdes i, er ikke det samme rum, vi kan agere i. Enzensberger kalder effekten «moralsk overbebyrdelse» - vi føler kravene om handling så overvældende, at vi resignerer og fortrænger - også i forholdet til det nære rum, hvori vi faktisk kan agere (Enzensberger, 1993). Derved blokeres de etiske fordringer, der udspringer af vores jødisk-kristne kulturgrundlag. Selve vores identitet bringes i tvivl.

I den verden, som nogen kalder postmoderne, er de store fortolkningssystemers moralske og historiske tyngde afløst af kaosteoriernes uendeligt komplekse vekselspil af kraftfelter. Udtrykt med en Kierkegaard-parafrase betyder denne kompleksitet os, at vi måske kan forstå historien baglæns - men ikke evner at forudsige den forlæns. Fysikken har for længst accepteret at kausalitet, gennemsnit og normalitet kun fungerer efter vore rationelle begreber, når vi opererer indenfor dele af «mellembølgeområdet» mellem astro- og partikelfysik. Også for humanvidenskaberne bliver det nødvendigt at acceptere, at netop det atypiske og det tilfældige rummer mutagene og evolution $x$ re potentialer - ja ligefrem kan ligge til grund for store gennembrud i menneskenes og kulturernes historie (Edgar Morin, 1990). Det udelukker ikke, at historiens gang tillige er underlagt kausale sammenhænge i klassisk forstand, men der optræder huller og spring i den rationaliserbare kausalitet, situationer hvor tilfældet tager over og skaber uforudsete men afgørende nye muligheder og begrænsninger. Deraf følger på den ene side de absolutte forudsigelsers umulighed og på den anden side muligheden og nødvendigheden af at søge de komplekse forklaringer, der skal omsætte begivenheder til erfaringer.

Historiefilosofien er således i dag konfronteret både med fremskridtstroens nederlag og med den rationalistiske analyses manglende evne til at løfte historieforstålsen ud over dilemmaet mellem det skabelonagtigt generaliserende og det ekstremt partikulariserende. Derfor er det blevet mondænt at tale om Historiens død. En ide, der på samme måde som tidligere ideen om Guds død, er et udtryk for tabet af en rodfrestet tro på et styrende princip i menneskets tilværelse. Et forsyn, der gav mål og mening. Guds død var en 
af rationalismens konsekvenser. Ikke således forstået at Gud blev fravalgt af rationalismens tænkere - for Spinoza eller Hegel var Guds eksistens ikke i modstrid med det rationelle. At studere verden for at afdække de rationelle love, der styrede den, var det samme som at finde ind til Guds sande væsen, der som noget iboende (immanens) kom til udtryk i matematikken, i naturlovene og i historiens fremadskriden. Men netop derfor behøvede de rationaliseringer over virkeligheden, som videnskaberne opstillede, kun i ringe grad det religiøse som et aktivt forklarende element. Og gradvist gled det religiøse ud af fokus samtidigt med, at det rationelle gled ind.

Men det rationelle historiesyn forblev alligevel tro mod sine narrative rødder $\mathrm{i}$ den jødisk-kristne opfattelse af menneskehedens historie som en fortælling, der førte os fra skabelse og syndefald til frelse og forløsning i paradisisk harmoni. $\mathrm{Nu}$ var det blot ikke længere messiansk intervention (transcendens), men historiens egen lovmæssige progression mod et stadigt højere civilisatorisk niveau, der skulle føre til frelsen - Paradis på jord (jvfr. Lutz Niethammer 1989, JeanFrançois Lyotard 1988).

Det er denne messiansk-rationalistiske historieopfattelse, der er afgået ved døden. Dødsprocessen blev indledt i Flanderns skyttegrave 1914-18. Dødssymbolet er Berlinmurens fald. Det er dels tegnet, der henviser til det fuldbragte sammenbrud for det monstrøst rationalistiske sovjet-projekt: at færdigkonstruere historien (og dermed også dræbe den) med skabelsen af det fuldkomne menneskesamfund. Murens fald er tillige tegnet, som henviser til åbningen af kaos efter den bipolære verdensordens sammenbrud.
Men nederlaget for en historieopfattelse betyder jo ikke, at Historien er død. Forandringerne er ikke hørt op, blot fordi vi er kommet i vildrede med, hvad der driver dem, og hvorhen de fører os. Ej heller er fremskridt en historisk umulighed, blot fordi vi har mistet troen på fremskridtet som den forandring, der entydigt bringer os endnu et skridt nærmere det jordiske Paradis (Jacques le Goff, 1994).

Det, der er sket, er snarere end historiens død, at mennesket (det europæiske) efter modernitetens sammenbrud er blevet hjemløst i tiden, fordi det ikke længere forstår sin samtid som en epoke på historiens vej fra det værre til det bedre. Tiden har mistet sin åbenlyse sammenhæng med det store historiske projekt.

\section{DEN GRANSELØSE VERDEN, ELLER DET GLOBALE PARADOKS}

Mennesket er ikke blot blevet hjemløst i tiden men også i rummet. De rumlige grænser omkring os er blevet diffuse. Globalisering er et af de ord, vi anvender for det forhold, at de nationale strukturer får stadigt hårdere konkurrence fra den verdensomspændende udveksling af informationer, varer, kapital, mennesker - og miljøproblemer (Minc, 1993, Beckouche, 1993). Problemet med globaliseringen i forhold til den kulturelle identitet er, at den paradoksalt nok opleves meget forskelligt. Globaliseringen har nemlig en social dimension, der giver den radikalt forskellige betydninger som fænomen.

Det er rimeligt at stille sig det spørgsmål, om ikke det globale perspektiv til dels er et privilegium for en elite, der føler sig tryg ved og hjemme i de internationale organisationer og de transnationale kon- 
cerner. En elite som kan kommunikere på fremmedsprogene og som færdes hjemmevant på internettet.

Derfor må vi også forstå, at de nationalistiske, etniske, racistiske og fundamentalistiske bevægelser henter næring $\mathrm{i}$ angsten og afmagtsfølelsen hos folk, der oplever det globale som uoverskuelighed - som et opbrud, der har placeret beslutninger, der vedrører deres dagligliv i fremmede byer: Bruxelles, Frankfurt, New York, Los Angeles, Tokyo, Osaka, Hongkong.

Er det med andre ord sådan, at den globalisme, der betyder udfordrende kompleksistet, rejser og variation for jetsettet, for de mindre priviligerede betyder angst og usikkerhed? Angst for flytning af arbejdspladser til Sydøstasien eller Baltikum, for social udstødning og for indvandring af fremmede, for overbelastning af den politiske vilje (hos de bedrestillede) til at opretholde den sociale tryghed (for de dårligst stillede).

Medens vi som museumsfolk næppe kan siges at tilhøre jetsettet, er det ikke vores arbejde, der trues af det globale marked. Hvis ikke vi forstår den forskel og vores egen relativitet, kan vi som museumsfolk blive ved med forgæves at appellere til en ny fælles global forståelse hos publikum til en identitet som globaliseringen i sin nuværende socialt lagdelte form alligevel aldrig vil formå at gøre til en socialpsykologisk meningsfuld størrelse for andre end et priviligeret mindretal. Vi kan kompromittere vore museer med moraliserende udstillinger, som kun bekræfter de allerede overbeviste om globaliseringens velsignelser.

Vi må derfor også forstå, at folk søger kompensation for globaliseringens manglende evne til at skabe socialpsykologisk meningsfuld identitet ved at søge andre holdepunkter: Det kan være fodboldklubben, religionen, banden eller nationen og dens historie. Der vil være konflikt undertiden voldelig - i det her, i all fald hvis vi skal tro på seere som Enzensberger (1993) og Milan Kundera (1993). Også museerne vil blive afsøgt af folk, der søger identitet. Det skal vi ikke tænke ilde om, men omgås med imødekommende ansvarlighed, der ikke understøtter falske myter men giver holdepunkter for både lokal identitet og globalt udblik.

\section{DET DESORIENTEREDE MUSEUM - ELLER DET SØGENDE?}

Evolutionismens udstillingsprincip (og funktionalismens), som stadigvæk overordnet behersker mange af de kulturhistoriske museer, fokuserer modsat renæssancens kunstkammer på det ordinare, det typiske - altså netop på det, der ubesværet lader sig indsætte $\mathrm{i}$ et serielt system. Det får historien til at fremtræde med en tilsyneladende selvfølgelighed, som, hvis der var dækning for den, ville gøre det ubegribeligt, at vi ikke er i stand til at forudsige den. Kaosteori vil i højere grad inddrage det ekstraordinære ikke som eksotika, men som et nødvendigt element i forståelsen af de store forandringer og dermed også som nødvendige for at forstå overraskelsen som en naturlig del af historien. Derfor appellerer den stærkt i en tid, der opleves som ekstraordinær i ordets egentlige betydning.

$\mathrm{Og}$ derfor har den traditionelle museale historiefortælling mistet sin autoritet. Når kunstmuseerne i dag af en kulturhistoriker som jeg opleves som mere centralt placerede $\mathrm{i}$ samtidens kulturliv end de kulturhistoriske, hænger det netop sammen med, at 
sammenbruddet af den evolutionært retningsbestemte orden ikke har været afgørende for kunstmuseerne på samme måde, som for de kulturhistoriske museer. Tvært imod kan kunstmuseerne ved at fokusere på den enkelte kunstners definition af sit univers, sin individuelle afsøgning af grænselande, spejle absolutternes fald og nutidens fraktalisering.

Dog bør man vel tilføje, at når absolutterne er faldet og den globale selvforståelse hedder kaos, så døjer også kunstneren med at finde autentiske grænser at gennembryde. Derfor udstiller også kunstmuseerne objekter med betydninger, som netop ikke nødvendigvis lader sig udlede af objekterne selv, fordi de ikke refererer til en alment tilgængelig kode - en ikonografi. Forståelsen af samtidens billeder vil ofte forudsætte kunstnerens verbale mediering - for eksempel, Joseph Beuys' manifeste Blitzschlag mit Lichtschein auf Hirsch på Frankfurts forunderlige museum for moderne kunst (Beuys, 1986). Til forskel herfra har Gainsboroughs samtid - inden for de øvre samfundslag - næppe haft vanskeligt ved samstemmende og umiddelbart at tyde den rurale symbolik i portrættet fra 1749 af Mr. and Mrs. Andrews.

Hvis de kulturhistoriske museer tidligere har kommunikeret orden og overblik som en del af et historisk spejl for samfundet dengang, da tid og rum havde en entydig progressiv retning - ja så må de i dag acceptere, at de skal spejle en ny tid på en ny måde. Museerne skal stadigvæk tjene samtidens bestræbelse på at forstå sig selv i et større rumligt og tidsmæssigt perspektiv. Men til forskel fra museernes "Gründerzeit», hvor der var mange svar og færre spørgsmål, må vi i dag udfylde vores rolle på en anden måde. Vi må i højere grad stille åbne spørgsmål, tematisere og stimulere associationer - end levere færdigpakkede modeller af virkeligheden.

De kulturhistoriske museer besidder en grundsubstans af en tyngde, som kan danne en værdifuld ballast $\mathrm{i}$ en desorienteret nutid. Museernes udstillinger, magasiner og arkiver bugner af bevismaterialer mod tanken om Historiens død - ja mod den opfattelse, at Historien overhovedet skulle være dødelig, så længe mennesket findes som art. Menneskehedens hele historie er historien om forandring og vækst. Det ses måske ikke så tydeligt i det forkortede tidsperspektiv, som ofte dominerer samtidens selvreflektioner. Det fremgår vel end ikke tydeligt nok af et udblik over de seneste to hundrede års historie, fordi de isoleret set ville kunne tolkes som anomali - en europæisk induceret sygelig global vækst. Men hvis vi udfolder det samlede kulturhistoriske perspektiv, der jo omfatter mindst 3 millioner år og alle klodens kulturer - fortidige som nutidige - så ser vi forandringen og væksten. En bevægelse som i det overordnede perspektiv med stedse kortere intervaller har forskubbet balancerne i retning af nye, højere kompleksistets- og energiniveauer målt på de materielle parametre. Det er på sin vis en banal historie - så banal at den næsten er profan, fordi den - hvis "Væksten" som begreb blot indsættes i samme position som tidligere "Fremskridtet" - truer med også i fremtiden at forlede til reduktionistiske historieforklaringer, der frakender mennesket ansvar og valg.

Ikke desto mindre er det nødvendigt at fastholde, at forandring og vækst er menneskelige grundvilkår gennem millioner af år. Vi kan ikke se bort herfra, blot fordi vi ikke længere kan anrette fænomenerne 
8 med en simpel forklaringsmodel - et anskueligt billede af "Historiens motor». Vi kan heller ikke fortrænge det "blot" fordi væksten i sig selv frembyder alvorlige økologiske problemer også for nutiden og dermed er blevet et ideologisk belastet begreb.

Det er alt for fristende, når de store forklaringskonstruktioner er styrtet i grus, også at se bort fra de store fænomener, som de dristige konstruktioner søgte at forklare. Det er nemmere at snævre perspektivet ind til formidling af genstandene som eksotika eller at formidle fortiden, som var den en ukompliceret tilstand snarere end en flertydig proces.

Men museerne har ikke mindre end før deres store opgave $\mathrm{i}$ at konfrontere publikum med essensfænomenerne. Bestemt ikke for at vi alene skal beskæftige os med makrohistorie. Men for at inddrage det lange historiske perspektiv som baggrund for det korte, og det globale historiske perspektiv som baggrund for det lokale. Museerne kan på den måde danne modvægt til en postmoderne partikularisering af historien - en modvægt til historieformidlingens banalisering i oplevelseskulturens sugende tomhed af hurtig omsætning.

Historie er ikke underholdning, det er kostbare erfaringer, som det også kan være underholdende at beskæftige sig med. Erfaringer er noget, vi bruger som grundlag for at forstå den øjeblikkelige situation og dens muligheder i et større perspektiv. Derfor gælder det ikke blot om at have erfaring, men også om at kunne kombinere den med det aktuelle.

Museerne kan hjælpe samtiden ved at drage konsekvensen af, at den kronologiske fremstilling ikke længere har en enty- dig mening. Det kan vi gøre ved at sætte vinduer ind, som åbner sigtelinjer mellem aktuelle temaer i nutiden og begivenheder i fortiden. Måske får stenalderbøndernes rydninger $i$ urskoven herhjemme for 6.000 år siden sat andre tanker i gang, dersom udstillingen også rummer et avisudklip om rydninger af regnskov på Borneo i dag. Altså økologi- og ressourcetematik - ikke pakket ind i færdige meninger og løsninger, men gerne præsenteret som associationsåbninger, der antyder lange linjer og mulige sammenhænge. De slesvigske krige kan formidles med vinduer til den krig, der nu foregår i Bosnien. Endnu en gang, formidling uden løftede pegefingre - men med stof til eftertanke.

Octavio Paz (1993) skriver om ophævelsen af rationalitetens serielle sønderdeling af tid og rum i Apollinaires digte. På samme måde kan vi måske tænke fremtidens museum. Ikke som ophævelsen af alle tidsmæssige og rumlige strukturer, men som ophævelsen af museernes forsimplende koordinatsystemer af tider og steder, der ordner fænomenerne efter deres indbyrdes udmålte afstand. Fremtidens museum skal måske i sin tanke snarere ligne en svamp end et $\mathrm{r} ø \mathrm{r}$ - en porøs struktur med mange åbninger og forbindelser, der bringer fænomener, der ligger hinanden fjernt i tid eller rum i kontakt, hvis de deler andre væsentlige egenskaber end tiden og stedet. 


\section{SUMMARY}

Museum and meaning - the fractal challenge

Museums are born out of the modern belief in progress, a future, and the undisputed supremacy of contemporary European culture. The museums with their chronologically and geographically sequenced exhibitions delivered so to speak the documentation of this system of beliefs.

Today we have severe doubts about the validity of the whole idea of continuous progress as an inherent feature of our culture in particular, and for that matter as the fate of mankind in general. We are no longer sure about the link between technological, and scientific development on the one hand, and the development of the quality of human life on the other.

The story of progress simply no longer forms part of our common narrative. Since this was the story, that our museums were built to tell, the museums too have lost their primary ability to reassure us by conveying a sense of direction amidst an accelerating flow of change.

The shift from an axial to a fractal perception of history, implied the end of the idea of a predictability, which has in turn led to the announcement of the death of history. This is hardly to be wondered at, since Rationalism itself earlier implied the retreat of God from a transcendent position (with the ability to intervene) in the shaping of history to an intrinsic position, as he, who once and for all had defined the laws, and thereby the course of history (cf., Hegel). Gradually God was left entirely out of the focus, and his death proclaimed (cf., Nietzsche).

However, the argument for proclaiming the demise of history is not entirely sound. It seems to confuse three different issues, that of predictability, that of progress, and that of change. If history is understood as predictability, it is obviously dead, or rather, one must doubt that it was ever alive. If history is taken as synonymous with progress, we must acknowledge, that progress is not a neutral concept.
In many quantitative interpretations of the word we have through our history progressed towards the ability to sustain higher population numbers, longer lives, and more energy consumption. In other, more qualitative interpretations it can rightfully be questioned whether human history is unambiguously a history of progress.

If history is defined as change, the present time does not seem to prove it dead.

We cannot doubt that change is at least one element, constantly present in human existence on all levels. It would be naive to claim that change itself has ceased, just because we have lost faith that it will predictably lead to progress, or just because for the time being, we cannot see beyond the market as the most successful way of organizing our economies .

The museum has lost its reference to the narrative of progress as the platform of understanding shared by the public. But it has not lost the theme of change as an essential element for understanding the human condition. So change and diversity are what I think museums should deal with, since this is what most people find themselves confronting. It also seems evident that we should turn our problem with the collapse of the axial conception of history into an advantage by breaking down the unilinear structure of our exhibitions, and instead turn them into a spongeous web of canals opening suggestive references between phenomena earlier segregated into the different time-space compartments of history.

\section{LITTERATUR}

Beuys, Joseph et.al., Ein Gespräch. Zürich 1986. Beckouche, Pierre, Industrie: un seul monde. Paris 1993.

Brøgger, Jan, Kultur Forståelse. Oslo1993.

Enzensberger, Hans Magnus, Aussichten auf den

Bürgerkrieg. Frankfurt a.M. 1993. 
Carsten Paludan-MÚller

10 Enzensberger, Hans Magnus, Die große Wanderung 33 Markierungen. Frankfurt a.M. 1992.

Georgel, Chantal (direction), La Jeunesse des musées. Paris 1994.

Goff, Jaccques, le, La vieille Europe et la nôtre. Paris 1994.

Hemer, Oscar (ed.) Kulturen $i$ den globala byn.

Lund 1994.

Hooper-Greenhill, Eilean, Museums, and the shaping og knowledge. London 1992

Jørgensen, Arne, Vico, Myte, historie og erkendelse. Århus 1992.

Kundera, Milan, Les testaments trahis. Paris 1993.

Lyotard, Jean-François, Le Postmoderne expliqué aux enfants. Paris 1988.

Minc, Allain, Le nouveau Moyen Âge. Paris 1993.

Morin, Edgar, Science avec conscience Paris 1990.

Niethammer, Lutz, Posthistorie, Ist die Geschichte zu Ende? Hamburg 1989.

Papadakis, Andreas C.(ed), Architectural Design No. 94, New Museums.London 1991

Paz, Octavio, Avantgardens solnedgang. Oslo 1993.

Sherman, D. and Rogoff (eds.) Museum Culture,

Histories, Discourses, Spectacles. London 1994.

Sloterdijk, Peter, Falls Europa erwacht. Frankfurt a.M. 1994.

Walsh, Kevin, The Representation of the past. London 1992.

Wright, Georg Henrik von, Myten om framsteget. Stockholm 1993.

Carsten Paludan-Müller er forhistorisk arkaolog, nå leder af Kulturhistorisk Museum i Randers. Arbejder konkret med utvikling af udstillingsmediet og desuden med en afhandling om arkeologi som makrohistorie. Adr: Kulturhistorisk Museum, Stemannsgade 2,

DK-8900 Randers. fax +45-86418649 